\title{
Direct quantitative differentiation between Prevotella intermedia and Prevotella nigrescens in clinical specimens
}

\author{
Rudolf Gmür and Thomas Thurnheer
}

Institute for Oral Microbiology and General Immunology, Centre for Dental, Oral Medicine and Maxillofacial Surgery, University of Zürich, Plattenstrasse 11, $\mathrm{CH}-8028$ Zürich, Switzerland
Author for correspondence: Rudolf Gmür. Tel: +41 1634 3306. Fax: +41 16344310. e-mail: gmuer@zzmk.unizh.ch

This paper describes a quantitative fluorescent in situ hybridization (FISH) assay for the differential identification of Prevotella intermedia and Prevotella nigrescens in clinical samples, and compares its performance with less discriminatory culture and quantitative immunofluorescence (IF) assays. Fluorescence-labelled oligonucleotide probes directed to specific 16S rRNA sequences of $\boldsymbol{P}$. intermedia, P. nigrescens, Prevotella pallens and Prevotella denticola were hybridized under stringent conditions with cultured reference strains or plaque samples from deep periodontal pockets. Probe specificity was defined with strains from multiple oral Prevotella species. The lower detection level of the assays was approximately $3 \times 10^{3}$ target cells per $\mathrm{ml}$ of plaquesample suspension. $P$. intermedia, $P$. nigrescens, $P$. pallens and $P$. denticola were detected in plaques with prevalences of $69,67,0$ and $28 \%$, respectively. On average, $3.9 \times 10^{6} P$. intermedia, $3.1 \times 10^{6} P$. nigrescens and $5.6 \times 10^{5}$ $P$. denticola cells were counted per positive sample. All three species were found almost exclusively in dense mixed aggregates. Quantitative FISH data agreed satisfactorily with corresponding IF data $(r=0.711)$. Both FISH and IF enumerations of the sum of $P$. intermedia and $P$. nigrescens markedly exceeded the c.f.u. counts of black-pigmented colonies in Porphyromonas gingivalis-free cultured subgingival plaques. The results demonstrate the validity of this new assay. Unlike established IF, culture, PCR or checkerboard DNA hybridization assays, this FISH assay differentiates quantitatively between $P$. intermedia and $P$. nigrescens, provides visual accuracy control, and offers insights into the spatial distribution of the target cells within a clinical sample.

Keywords: fluorescent in situ hybridization, 16S rRNA, subgingival plaque, periodontitis

\section{INTRODUCTION}

The human oral cavity harbours a variety of moderately saccharolytic anaerobic species of the bacterial genus Prevotella, some of which may have clinical significance. The two most prevalent species of the group are Prevotella intermedia and Prevotella nigrescens. Formerly considered a single species, they were separated 10 years ago (Shah \& Gharbia, 1992; Frandsen et al., 1995) after multiple DNA homology studies (van Steenbergen et al., 1982; Johnson \& Holdeman, 1983; Moncla et al., 1988; Fukushima et al., 1992), serological experiments

Abbreviations: FISH, fluorescent in situ hybridization; IF, indirect immunofluorescence.
(Gmür \& Wyss, 1985; Nakazawa et al., 1988), isoenzyme screenings (Shah \& Gharbia, 1992; Frandsen et al., 1995) and whole-protein analyses (Shah \& Gharbia, 1992) had provided evidence for at least two distinct subgroups. Several investigations reported significant differences in the prevalence and/or abundance of the two species in samples collected from various oral sites (Moore et al., 1987; Dahlén et al., 1990; Fukushima et al., 1992; Gharbia et al., 1994; Gmür \& Guggenheim, 1994; Baumgartner et al., 1999). For example, when investigating the predominant cultivable microbiota in samples from adults, Moore et al. (1987) detected five times as many $P$. intermedia as $P$. nigrescens c.f.u. in periodontal pockets, but found seven times more $P$. nigrescens than $P$. intermedia at healthy sites. Or, in a 
study leading to similar conclusions, Dahlén et al. (1990) identified $2 / 3$ of their $P$. intermedia-like isolates from 'destructive periodontal disease' as $P$. intermedia, whereas $75 \%$ of the isolates from healthy control subjects were $P$. nigrescens. Such findings lead to the hypothesis that $P$. intermedia could be a periodontal pathogen (reflected by its inclusion as an indicator organism in several microbiological diagnostic kits for periodontal diseases), whereas $P$. nigrescens is considered a marker of relative periodontal health.

Phenotypically, the two species are very similar. Biochemical or serological differentiation is difficult, laborious and sometimes unreliable (Gmür \& Wyss, 1985; Shah \& Gharbia, 1992; Gharbia et al., 1994; Frandsen et al., 1995; Dahlén et al., 1996; Debelian et al., 1996; Mättö et al., 1996b; Paquet \& Mouton, 1997; Baumgartner et al., 1999; Lie et al., 2001). Therefore, investigations now employ semi-quantitative checkerboard DNA probe assays (Socransky et al., 1994) or PCR-based assays, of which multiple variations have been described, to differentiate between $P$. intermedia and $P$. nigrescens. So far, PCR-based assays have yielded only qualitative data, that is they were used either to type clonal black-pigmented colonies derived from primary cultures (Mättö et al., 1996a, b; Conrads et al., 1997; Guillot \& Mouton, 1997; Baumgartner et al., 1999; Haraldsson \& Holbrook, 1999; Premaraj et al., 1999; Robertson et al., 1999) or to directly determine the presence or absence of the two species in clinical samples (Ashimoto et al., 1996; Riggio et al., 1998; Stubbs et al., 1999; Mullally et al., 2000; Siqueira et al., 2001). To our knowledge, a quantitative real-time PCR assay has not yet been described, and fluorescent single-cell-specific assays are not available.

The motivation for the present study was our finding, in an ongoing investigation assessing selected microbiota in dental plaque from the gingival margins of Chinese patients with either necrotizing ulcerative gingivitis or gingivitis, that the former group had a significantly higher load of serologically detectable $P$. intermedia/ $P$. nigrescens cells than the gingivitis group (data not shown). In light of the postulated different roles of the two species as periodontal pathogens, it seemed important to identify and quantify them differentially. Thus, the aim of the present study was to develop direct, quantitative, species-specific $P$. intermedia and $P$. nigrescens detection assays and to evaluate their performance in comparison with culture and indirect immunofluorescence (IF) applied, in parallel, to a set of subgingival plaque samples. Based on the available infrastructure and experience, we opted for fluorescent in situ hybridization (FISH) using DNA probes to species-specific $16 \mathrm{~S}$ rRNA sequences to target the two species.

\section{METHODS}

Strains, dental plaque samples and cultivation. Strains of oral bacteria were grown anaerobically $\left(85 \% \mathrm{~N}_{2}, 10 \% \mathrm{H}_{2}\right.$, $5 \% \mathrm{CO}_{2}$ ) at $37^{\circ} \mathrm{C}$ in fluid universal medium (Gmür \&
Guggenheim, 1983) enriched with 5\% horse serum and harvested after 12-24 h from the exponential phase of growth.

Subgingival plaque samples $(n=39)$ were obtained, with paper points (Gmür et al., 1989), from periodontal pockets of 16 patients (14 female) with a mean age of 45.5 years (range $25-$ 67 years). The subjects had been referred to our institute for microbial testing because of refractory chronic periodontitis (Armitage, 1999). The sampled pockets had a mean probing depth of $6.2 \pm 1.3 \mathrm{~mm}$ (range $5-10 \mathrm{~mm}$ ). Within $1 \mathrm{~h}$ of harvesting, samples were vortexed for $30 \mathrm{~s}$ at the maximum setting and split into different aliquots. Aliquots selected for FISH were frozen at $-20{ }^{\circ} \mathrm{C}$ until used. Aliquots for IF and cultivation were processed immediately. Those reserved for cultures were serially diluted from $10^{-1}$ to $10^{-5}$ in $0.9 \% \mathrm{NaCl}$. A $50 \mu \mathrm{l}$ aliquot from each dilution was distributed on Columbia blood agar base (Oxoid) supplemented with $5 \%$ haemolysed human blood using a spiral diluter (Spiral System), and plates were incubated anaerobically for $96 \mathrm{~h}$ at $37^{\circ} \mathrm{C}$. Colony-forming units (c.f.u.) were counted using a stereomicroscope, selectively assessing plates with an optimum concentration of colonies.

Cell fixation and preparation of multiwell slides. For FISH assays of cultured bacteria, strains were washed once in $0.9 \%$ $\mathrm{NaCl}$, resuspended in sterile PBS at $\mathrm{pH} 7 \cdot 4$, and fixed $(20 \mathrm{~min}$, $\left.4{ }^{\circ} \mathrm{C}\right)$ by mixing the cell suspension $1: 10(\mathrm{v} / \mathrm{v})$ with $4 \%$ freshly prepared paraformaldehyde solution (Manz, 1999). Thereafter, the cells were pelleted by centrifugation at $10000 \mathrm{~g}$, resuspended in $50 \%$ ethanol, and either directly spotted on precleaned 18- or 24-well microscope slides (CelLine Associates) or stored at $-20{ }^{\circ} \mathrm{C}$ until used. Air-dried slides were dehydrated in 50, 80 and $100 \%$ ethanol $(3 \mathrm{~min}$ each). For FISH assays of plaque samples, $10 \mu$ diluted $(1: 5$ or $1: 10)$ plaque suspension per well was dropped onto 18 - or 24 well slides, air-dried and then fixed immediately $(20 \mathrm{~min}$, $4{ }^{\circ} \mathrm{C}$ ) by inserting the slide in a $50 \mathrm{ml}$ centrifuge tube containing $4 \%$ paraformaldehyde. For IF assays, cultured bacteria or subgingival plaque samples were used to coat 18or 24-well slides and fixed with methanol as described (Gmür et al., 1989). Prior to the coating stage, subgingival plaque samples had been centrifuged at $10000 \mathrm{~g}$ for $5 \mathrm{~min}$, resuspended for $3 \mathrm{~min}$ in $0.83 \% \mathrm{NH}_{4} \mathrm{Cl}$ to lyse erythrocytes, recentrifuged, resuspended in $0.9 \% \mathrm{NaCl} / 0.02 \% \mathrm{NaN}_{3} /$ $0.00025 \%$ cetyltrimethylammonium bromide and stored at $-20{ }^{\circ} \mathrm{C}$ until used.

FISH. Custom-synthesized oligonucleotide probes, labelled at the $5^{\prime}$-ends with Cy3 or 6-FAM, were purchased from Interactiva. Probes were designed according to the criteria described by Manz (1999), using programs and rRNA sequence information from Ribosomal Database Project II (Maidak et al., 1999) (http://rdp.cme.msu.edu/html/) and the National Center for Biotechnology Information (http:// www.ncbi.nlm.nih.gov/BLAST/). The sequences of the probes employed for P. intermedia, $P$. nigrescens, Prevotella denticola and Prevotella pallens are listed in Table 1. The probes were used at a final concentration of $5 \mathrm{ng} \mu \mathrm{l}^{-1}$, except for competitor probes, which were used at $50 \mathrm{ng} \mu \mathrm{l}^{-1}$. FISH was performed using a modification (Thurnheer et al., 2001) of the method described by Manz (1999), except that the length of the hybridization period was set to $150 \mathrm{~min}$. Optimum reactivity conditions for the probes with target and non-target strains were determined as described (Thurnheer $e t$ al., 2001). The universal bacterial probe EUB338 (Amann et al., 1995) served as a positive control. Fluorescence intensity was graded using an arbitrary five-step scale, where 0 (no fluorescence above background) and $1+$ (very faint fluor- 
Oral P. intermedia and P. nigrescens enumeration

Table 1. Probe sequences, target sites and optimum formamide concentrations for in situ hybridization

\begin{tabular}{|lllcc|}
\hline Probe & \multicolumn{1}{c}{ Target } & \multicolumn{1}{c}{ Sequence $\left(\mathbf{5}^{\prime} \rightarrow \mathbf{3}^{\prime}\right)^{*}$} & Site† & $\begin{array}{c}\text { Formamide } \\
(\mathbf{\%})\end{array}$ \\
\hline EUB338 & Bacteria & GCTGCCTCCCGTAGGAGT & $338-355$ & $5-40$ \\
Pint657 & P. intermedia & TCCGCATACGTTGCGTGCA & $657-675$ & 40 \\
Pint649 & $P$. intermedia & CGTTGCGTGCACTCAAGTC & $649-667$ & 40 \\
Pnig657 & $P$. nigrescens & TCCGCCTGCGCTGCGTGTA & $657-675$ & 40 \\
Ppal654 & $P$. pallens & GCATACGTTGCGTGTACTC & $654-672$ & 40 \\
Ppal654comp & P. intermedia & GCATACGTTGCGTGCACTC & $654-672$ & 40 \\
Ppal186 & $P$. pallens & CATATCTGATGCCATCAATG & $186-204$ & 10 \\
Pden654 & $P$. denticola & GCCGGCGTTGCGCGTACTC & $654-672$ & 40 \\
\hline
\end{tabular}

* An underlined letter indicates a single mismatch between P. intermedia and P. pallens at position 658.

†Targeted 16S rRNA region (E. coli numbering; Brosius et al., 1981).

escence) were considered negative signals, and $2+$ (weak), $3+$ (strong) and $4+$ (brilliant fluorescence) were considered positive signals.

IF. Porphyromonas gingivalis and the Prevotella intermedia/ $P$. nigrescens group of bacteria were labelled with $\mathrm{mAbs}$ 61BG1.3 (Gmür et al., 1988) and 37BI6.1/39BI1.1.2 (Gmür \& Guggenheim, 1983), respectively. Specific mAb binding by target cells was visualized (Gmür et al., 1989) by using consecutive incubations with a mouse anti-rat $\kappa$-chain $\mathrm{mAb}$ (MARK-1; Bazin et al., 1984) (an optional step used only in conjunction with the rat $\mathrm{mAb}$ detecting $P$. intermedia/ $P$. nigrescens), a mixture of biotinylated goat anti-mouse $\operatorname{Ig} G$ and IgM (both from Sigma) and avidin-fluorescein isothiocyanate (Sigma). The lower detection limit of the IF assay is $3 \times 10^{3}$ (or $0.003 \%$ ) for a typical sample from a periodontal pocket containing approximately $10^{8}$ bacteria (Gmür, 1995).

Microscopy. FISH- and IF-stained slides were read with an Olympus BX60 epifluorescence microscope [Olympus Optical (Schweiz)] equipped with phase-contrast, an HBO $103 \mathrm{~W} / 2$ mercury photo optic lamp (Osram) and Olympus filter sets U-MNIBA (6-FAM), U-MA41007 (Cy3) and BX-DFC5 (6$\mathrm{FAM} / \mathrm{Cy} 3)$. The samples were evaluated for the number of fluorescent bacteria per $\mathrm{ml}$ of sample as described (Gmür \& Guggenheim, 1994), monitoring either randomly selected fields that covered, in total, between $1 / 100$ and $1 / 2$ of a well or an entire well, depending on the density of positive cells. Colour micrographs were taken with a digital Olympus Camedia 3030 camera, transferred to a Macintosh G3 personal computer and processed using the standard software provided with the camera and РнотоSнор 6.0 (Adobe) without any qualitative changes to the raw images.

\section{RESULTS}

\section{Specificity of oligonucleotide probes}

In specificity tests with reference strains from various Prevotella species, probes Pnig657, Ppal186 and Pden654 showed the anticipated specificity for $P$. nigrescens, $P$. pallens and $P$. denticola, respectively (Table 2). Probe Pint657 identified all $P$. intermedia strains, but also hybridized to isolates of $P$. pallens. To avoid such crossreactivity, a second probe to $P$. intermedia (Pint649) was evaluated that had the single mismatch at nucleotide 658 shifted to the central region of the probe. Pint 649 proved to be specific for $P$. intermedia and labelled all $P$. intermedia strains tested. For $P$. pallens, a second probe (Ppal654) was employed as well, but in this case with the aim of obtaining stronger fluorescence intensity. It revealed specificity for $P$. pallens if an unlabelled competitor sequence (Ppal654comp) was added during hybridization to prevent cross-reactivity with $P$. intermedia (Table 2). All probes directed against target sequences between nucleotides 645 and 675 led to very intensive fluorescence $(3-4+)$, whereas fluorescence obtained with Ppal186 was much weaker and was graded as $2-3+$. None of the probes hybridized to tested strains of other taxa (data not shown) or to labelled bacteria in plaque samples with atypical target-cell morphology.

\section{Quantitative detection, using FISH, of target bacteria in subgingival plaque samples}

Fig. 1 shows a field of a representative plaque sample stained for P. intermedia (with probe Pint649-Cy3; red) and P. nigrescens (with Pnig657-FAM; green). The two corresponding images were made in fluorescence mode using a dual filter set (Fig. 1a) and in phase-contrast mode (Fig. 1b). They demonstrate the main presence of both species in heterogeneous aggregates ranging in size from a few to several hundred cells. Planktonic P. intermedia and $P$. nigrescens bacteria accounted for only a very minor proportion $(<5 \%)$ of the cells detected. Aggregates colonized by both species were not uncommon, but, in general, the cells of one species strongly outnumbered those of the other. Both P. intermedia and $P$. nigrescens presented in plaque as small cocci or very short rods. $P$. denticola cells were always rod-shaped and longer than $P$. intermedia or P. nigrescens cells (not shown).

Results from the application of probes Pint657 and Pnig657 to subgingival plaque samples are summarized 
Table 2. Probe specificity assessed by FISH with various Prevotella species

\begin{tabular}{|c|c|c|c|c|c|c|}
\hline \multirow[t]{2}{*}{ Species } & \multicolumn{6}{|c|}{ Reactivity* with probe: } \\
\hline & Pint657 & Pint649 & Pnig657 & $\begin{array}{c}\text { Ppal654+ } \\
\text { Ppal654 } \\
\text { comp }\end{array}$ & Ppal186 & Pden654 \\
\hline P. buccae & $0 / 1$ & $0 / 1$ & $0 / 1$ & $0 / 1$ & $0 / 1$ & $0 / 1$ \\
\hline P. corporis $†$ & $0 / 2$ & $0 / 2$ & $0 / 2$ & $0 / 2$ & $0 / 1$ & $0 / 2$ \\
\hline P. denticola $†$ & $0 / 3$ & $0 / 3$ & $0 / 3$ & $0 / 2$ & $0 / 2$ & $3 / 3$ \\
\hline P. intermedia $\dagger$ & $8 / 8$ & $7 / 7$ & $0 / 8$ & $0 / 8$ & $0 / 7$ & $0 / 7$ \\
\hline P. loescheii & $0 / 1$ & $0 / 1$ & $0 / 1$ & $0 / 1$ & $0 / 1$ & $0 / 1$ \\
\hline P. melaninogenica & $0 / 2$ & $0 / 2$ & $0 / 2$ & $0 / 2$ & $0 / 2$ & $0 / 2$ \\
\hline P. nigrescens $\dagger$ & $0 / 8$ & $0 / 6$ & $8 / 8$ & $0 / 7$ & $0 / 6$ & $0 / 6$ \\
\hline P. oralis $\dagger$ & $0 / 1$ & $0 / 1$ & $0 / 1$ & $0 / 1$ & $0 / 1$ & $0 / 1$ \\
\hline P. oris $\dagger$ & $0 / 1$ & $0 / 1$ & $0 / 1$ & $0 / 1$ & $0 / 1$ & $0 / 1$ \\
\hline P. oulora & $0 / 1$ & $0 / 1$ & $0 / 1$ & $0 / 1$ & $0 / 1$ & $0 / 1$ \\
\hline$P$. pallens $\dagger$ & $3 / 3$ & $0 / 3$ & $0 / 3$ & $3 / 3$ & $3 / 3$ & $0 / 3$ \\
\hline P. veroralis & $0 / 1$ & $0 / 1$ & $0 / 1$ & $0 / 1$ & $0 / 1$ & $0 / 1$ \\
\hline
\end{tabular}

* Number of positive strains versus total number of strains tested.

†Includes the type strain of the species.

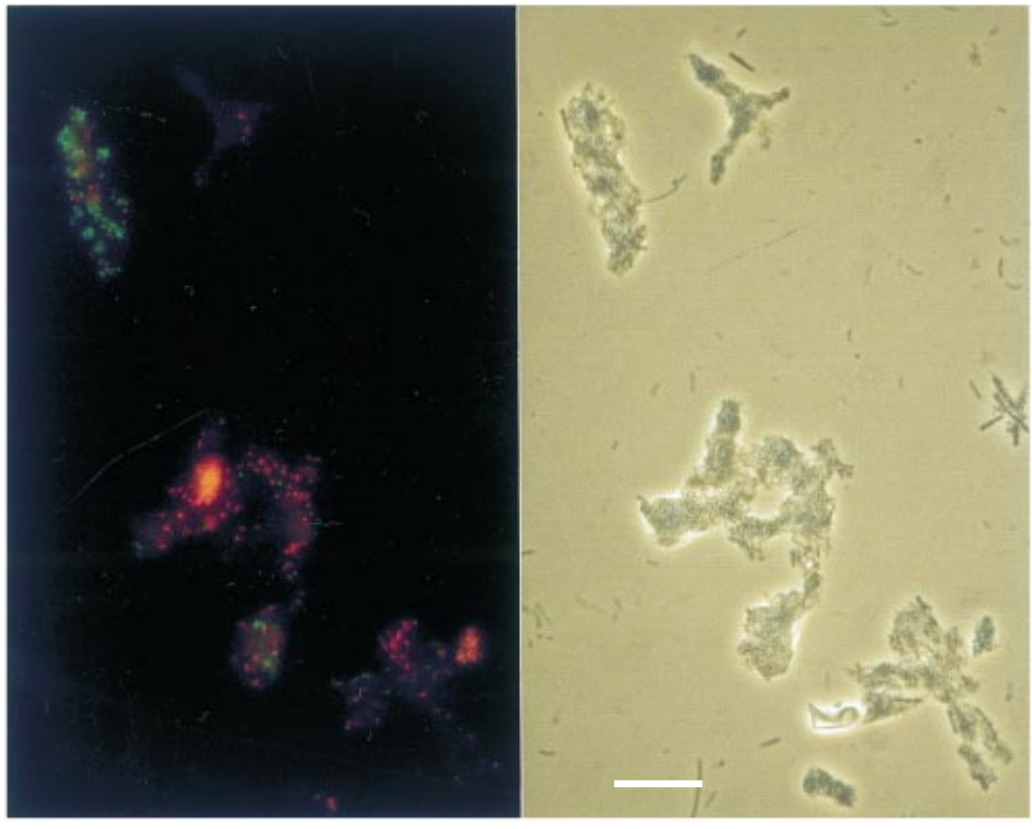

Fig. 1. Subgingival plaque sample no. 36 stained by in situ hybridization with probes Pint649-Cy3 and Pnig657-FAM with specificity for $P$. intermedia (red) and $P$. nigrescens (green), respectively. Epifluorescence (a) and phase contrast (b) micrographs from one representative field are shown. Labelled cells are located almost exclusively within dense mixed aggregates. Often both species are present within an aggregate, but, in general, one species strongly outnumbers the other. Bar, $10 \mu \mathrm{m}$.

in Fig. 2(a). P. intermedia was detected in 27 of $39(69 \%)$ and $P$. nigrescens in 26 of $39(67 \%)$ samples. P. pallens was not detected in spite of using, with Pal186 and Ppal654 (plus Ppal654comp), two distinct probes. $P$. denticola occurred in 10 of 39 (26\%) samples. Nine samples $(23 \%)$ were negative for all monitored Prevotella species. Of the samples positive for P. intermedia or $P$. nigrescens, $77 \%$ harboured both organisms. The ratio between $P$. intermedia and $P$. nigrescens in doublepositive samples varied considerably between different samples and thus provided no hints as to possible synergistic or antagonistic effects between these two species. However, high levels of $P$. nigrescens $\left(>10^{6}\right.$ cells per ml sample) always accompanied similarly high levels of P. intermedia, whereas the opposite was clearly not the case (Fig. 2a).

Although P. pallens was not detected with Ppal186 and Ppal654 (plus Ppal654comp) in the present collection of plaque samples, we opted to re-examine the presence of 
(a) 日 P. intermedia with probe Pint657

P. nigrescens with probe Pnig657

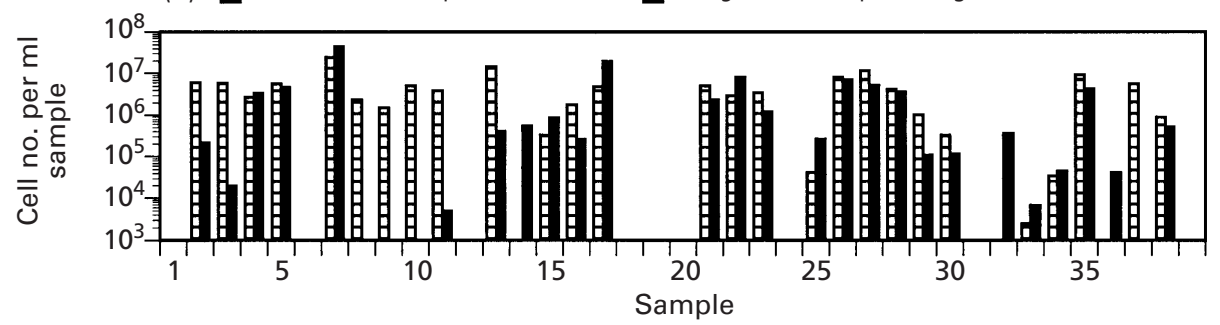

(b) $\quad$ P. intermedia with probe Pint657 $\square$ P. intermedia with probe Pint649

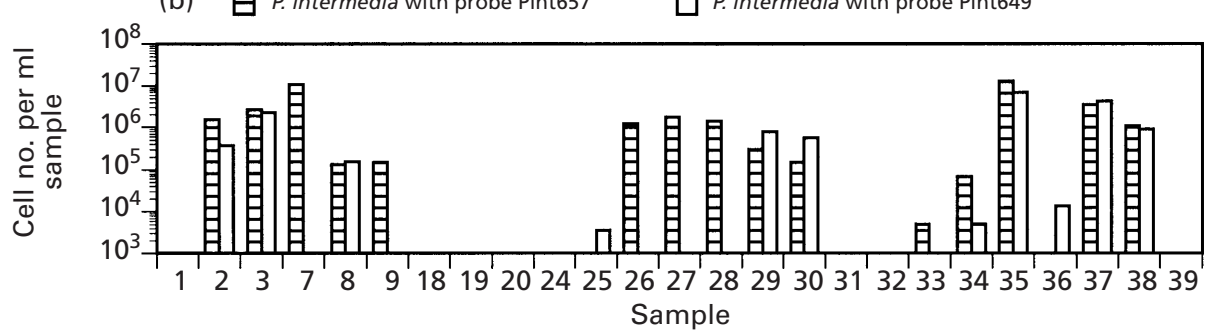

Fig. 2. Bar chart showing the prevalence and number of $P$. intermedia and $P$. nigrescens cells in subgingival plaque samples analysed by FISH. (a) Data obtained using probes Pint657 and Pnig657 to identify $P$. intermedia and $P$. nigrescens, respectively. (b) Comparison of the enumeration of $P$. intermedia with probes Pint657 and Pint649, which, based on the available information on bacterial rRNA gene sequences from public data banks, should be specific for $P$. intermedia. Within the recognized target region, $P$. intermedia has at least two mismatches with any other known taxa, except $P$. pallens, which has one mismatch at position 658 .

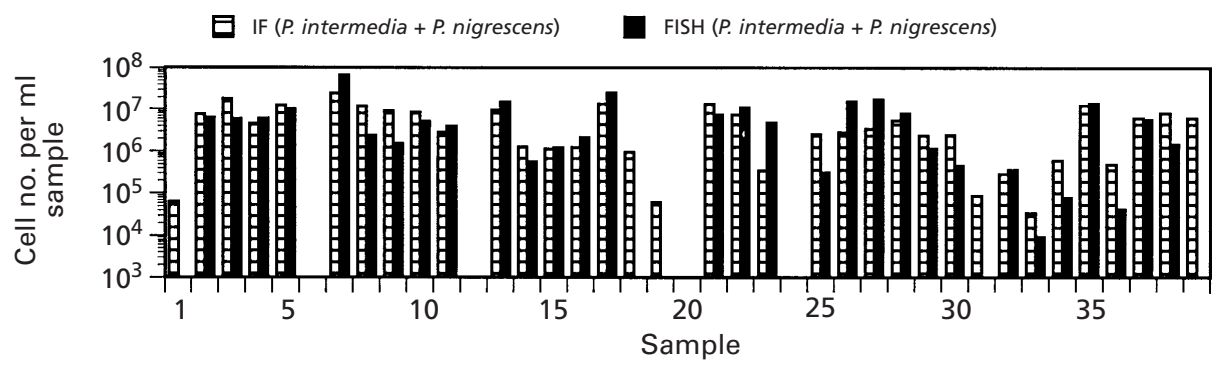

Fig. 3. Comparison of FISH with IF for the enumeration of $P$. intermedia/P. nigrescens in subgingival plaque. Since the IF assay with mAbs 37BI6.1 and 39BI1.1.2 cannot differentiate between the two species, the IF data are compared with the sum of $P$. intermedia and $P$. nigrescens cells detected by FISH.

P. intermedia with probe Pint649, which had not revealed cross-reactivity with $P$. pallens (Table 2 ). Because of the limited sample size, the analysis had to be restricted to 25 samples. Results are summarized in Fig. 2(b). Eight samples were negative with both probes; four more showed cell numbers of approximately $10^{4}$ cells or less and do not qualify for comparisons because the counts were too close to the lower detection limit of the assay (approximately $3 \times 10^{3}$ cells per ml sample). Of the 13 remaining samples, eight displayed very good agreement between the cell numbers detected by Pint657 and Pint649. However, five samples, three of which (nos 26-28) were from the same patient, were positive with Pint657 and negative with Pint649; this strongly indicates that the former probe is detecting another unidentified organism of identical morphology to $P$. intermedia.

\section{Comparison of FISH data with IF and culture data}

$P$. intermedia and $P$. nigrescens enumerations by FISH and IF are compared in Fig. 3. Because the two species are not discriminated by the IF assay, the IF data had to be plotted against the sum of $P$. intermedia and $P$. nigrescens as detected with probes Pint657 and Pnig657. The results demonstrated a satisfactory correspondence $(r=0.710)$ between the two assays, except for five samples that were positive by IF but negative by FISH.

For a comparison of FISH and IF with culture, Fig. 4 shows data from Columbia blood agar cultures plotted against the cell numbers of $P$. intermedia plus $P$. nigrescens as detected by both IF and FISH. Only Porphyromonas gingivalis-free samples (as determined by IF with mAb 61BG1.3; data not shown) were considered. It is evident that, with most samples, IF and 


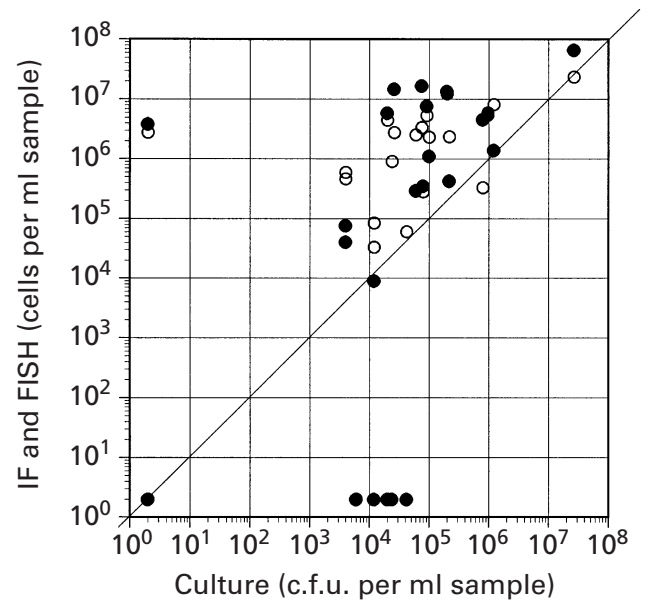

Fig. 4. Scattergram comparing FISH and IF with culture for the quantitative detection of $P$. intermedia/P. nigrescens in subgingival plaques. The $45^{\circ}$ line indicates a theoretical ideal relationship between the black-pigmented c.f.u. and IF or FISH counts. The IF assay was performed with mAbs 37BI6.1 and 39BI1.1.2, and the FISH assay with probes Pint657 and Pnig657. All samples were free of Porphyromonas gingivalis. To facilitate reading, negative values were assigned a value of $2.0, P i+P n$ by IF;, $\mathrm{Pi}+\mathrm{Pn}$ by FISH.

FISH enumerations exceed c.f.u counts considerably, on average by factors of 87 and 70 , respectively. Again, this finding clearly reflects the main presence of these organisms in small, virtually undisruptible, aggregates, described in Fig. 1.

\section{DISCUSSION}

The distribution and number of $P$. intermedia and $P$. nigrescens cells in 39 subgingival plaque samples from severe periodontitis patients were studied by applying a quantitative FISH assay directly to fixed specimens. Samples were further monitored for the recently described species $P$. pallens (Könönen et al., 1998), which has a close genetic relationship to P. intermedia, and for $P$. denticola, which, like P. intermedia, was described as being associated with gingivitis and periodontitis (Wu et al., 1992). The results from our FISH experiments showed that $P$. intermedia and $P$. nigrescens colonized the investigated subgingival plaque samples with virtually identical prevalence (69 versus $67 \%$ ) and density (approx. $3 \times 10^{6}$ cells $\mathrm{ml}^{-1}$ ). They closely resemble those reported by Mättö et al. (1996b). Previously, P. intermedia, but not P. nigrescens (the former Bacteroides intermedius genospecies II or homology group 8944), has been associated with periodontitis (Moore et al., 1987; Dahlén et al., 1990; Gharbia et al., 1994; Mättö et al., 1996b). However, this association was based as much on the absence or minimal presence of $P$. intermedia at healthy or weakly inflamed sites as on its abundance in deep periodontal pockets. Apparently, $P$. nigrescens colonizes more diverse niches of the oral cavity (Moore, 1987; Mättö et al., 1996b; Baumgartner et al., 1999). P. pallens was not observed in the present study in spite of the application of two probes with specificity for distinct regions of the $16 \mathrm{~S} \mathrm{rRNA}$ of the species. It is not possible to compare our finding with previously reported data since earlier studies did not use techniques that would specifically recognize $P$. pallens. $P$. denticola was detected with a low prevalence $(26 \%)$ and in slightly lower cell numbers than $P$. intermedia and $P$. nigrescens. It is the most frequently detected plaque organism of a group of Prevotella species that also includes Prevotella melaninogenica and Prevotella loescheii, and possibly could be confused with $P$. intermedia/P. nigrescens when screening blood agar cultures for black-pigmented colonies, although all three species frequently display weak red-brown or no pigmentation (Wu et al., 1992). We used the probe for $P$. denticola in the present study to obtain an idea of the abundance of this micro-organism, which had until then been neglected in our analyses of plaques from periodontitis patients.

The rapid and accurate identification and enumeration of black-pigmented anaerobes from highly complex microbial communities such as subgingival plaque are difficult tasks. Many of the available techniques for differentiation between $P$. intermedia and $P$. nigrescens rely on culture as the initial step; black-pigmented colonies are selected for and counted, and then a variety of 'secondary' techniques are used to identify representative colonies (Dahlén et al., 1990; Mättö et al., 1996b; van Steenbergen et al., 1997; Conrads et al., 1997; Debelian et al., 1997; Haraldsson \& Holbrook, 1999; Robertson et al., 1999). This approach has several disadvantages. First, it is expensive and time-consuming because of a lengthy incubation period. Second, data from this study (Fig. 4) demonstrate clearly that culture substantially underestimates the cell numbers of $P$. intermedia and $P$. nigrescens in subgingival plaque. This is not surprising in the light of the overwhelming association of both species with dense mixed bacterial aggregates (Fig. 1) that are not disrupted by brief sonication and lengthy vortexing $(60 \mathrm{~s})$. Similar evidence has been reported previously (Loesche et al., 1992; Giertsen et al., 2000); nevertheless, the problem that aggregation poses to quantitative culture analyses remains widely neglected. Techniques that do not require culturing and which differentiate between $P$. intermedia and $P$. nigrescens are available (various PCR-based assays, checkerboard DNA-DNA hybridization), but so far they have the disadvantage of yielding only qualitative (Ashimoto et al., 1996; Riggio et al., 1998; Stubbs et al., 1999; Mullally et al., 2000), or at best semiquantitative, data (Socransky et al., 1994; Tanner et al., 1998). Clearly, there is a need for a rapid and objectively quantitative procedure for the direct quantification of the two species in clinical samples to investigate their postulated roles in oral health and disease in more detail. We feel that our FISH assay with new probes to species-specific stretches of $16 \mathrm{~S}$ rRNA of $P$. intermedia, $P$. nigrescens, $P$. pallens and $P$. denticola, described in this work, provides such a tool. Unlike currently used IF assays, the FISH assay can differentiate between $P$. 
intermedia, P. nigrescens and P. pallens. Like IF, it offers sensitive, qualitative and quantitative monitoring of single fluorescent cells in clinical samples, and has a lower detection limit of slightly more than $10^{3}$ cells ml ${ }^{-1}$ for samples containing approximately $10^{8}$ bacteria. (Such cell densities require sample dilutions of $1: 5$ or $1: 10$ for the coating of $4 \mathrm{~mm}$ wells with $10 \mu \mathrm{l}$. If the minimum requirement for a positive score is set to at least three positive cells per well, it follows that the lower detection limit at a $1: 10$ dilution is $3 \times 10^{3} \mathrm{ml}^{-1}$; Gmür, 1995). Fluorescence assays for bacteria are always confronted with the possible presence of autofluorescence-emitting bacteria or of non-specifically fluorescent particles. In the present study, autofluorescence with the characteristic orange-red colour of the Cy3 label or the fluorescein-isothiocyanate-like colour of 6-FAM was not observed. Fluorescent particles were always present but could be recognized readily because of the extremely intensive fluorescence and the irregular shapes. A comparison of the performance of FISH and IF generally showed good correspondence (Fig. 3), in particular if one considers that increased data variability had to be expected because cells were distributed unevenly (in aggregates) in the wells of the microscope slide and only a part of the entire well was monitored. Interestingly, five samples were positive for $P$. intermedia/P. nigrescens by IF but not by FISH. The most likely explanation for this observation is that mAbs 37BI6.1 and 39BI1.1.2 could bind to another, so far unidentified, species. We had noted recently that both mAbs labelled strains of the newly described species $P$. pallens (unpublished observation), but, according to the FISH data with probes Ppal186 and Ppal654 (+Ppal654comp), P. pallens was not present in the samples studied.

In designing probes for the FISH assay described, we preferentially targeted the highly variable $5^{\prime}$ half of helix 23 of the 16S rRNA with nucleotides 645-680 (Escherichia coli numbering; Brosius et al., 1981). This region has yielded numerous bright oligonucleotides with specificity at genus or species level (Amann et al., 1995; Fuchs et al., 1998) (our unpublished data). All five probes from this study against this region were usable at high formamide concentrations and yielded very strong fluorescence signals. In contrast, a P. intermedia-specific probe targeted to nucleotides 620-638 gave completely negative results (data not shown). P. intermedia and $P$. pallens differ within the stretch from nucleotides 645680 only at position 658. Thus, probes Pint657 and Pint649 (both 19-mer oligonucleotides) each have this single mismatch with $P$. pallens, which, however, is located either peripherally or centrally. Not unexpectedly (Manz, 1999), the peripheral mismatch location in probe Pint657 led to cross-reactivity with $P$. pallens at medium fluorescence intensities, whereas Pint649 with the mismatch in the centre of the probe proved to be $P$. intermedia-specific. Conversely, probe Ppal654 was only negative with $P$. intermedia if an unlabelled competitor probe was added in excess to prevent the hybridization of the fluorescent Ppal654 to P. intermedia. As all samples of this study appeared to be $P$. pallens-free (no bacteria positive with Ppal186 or Ppal654/Ppal654comp could be detected), one would expect FISH with Pint657 and Pint648 to result in approximately the same number of fluorescent bacteria. This was indeed the case with most samples, which underlines the credibility of this quantitative assay. However, five exceptional samples, three from one patient, were noted. In these samples, Pint657 labelled between $10^{5}$ and $10^{7}$ positive bacteria that remained unlabelled by Pint649. Positive cells had the typical morphology of plaque-derived P. intermedia. The data suggest that Pint657 may detect (in addition to 'normal' $P$. intermedia) an unidentified variant or different taxa with at least one mismatch within the rRNA region (nucleotides 657-667) covered by both probes.

In summary, the results presented in this investigation show good discrimination between $P$. intermedia and $P$. nigrescens by oligonucleotide probes, and demonstrate the advantages of the application of a FISH assay specific for these species in comparison to both culture and IF.

\section{ACKNOWLEDGEMENTS}

We thank Martin Gander and Yvonne Helweg for excellent technical assistance.

\section{REFERENCES}

Amann, R. I., Ludwig, W. \& Schleifer, K.-H. (1995). Phylogenetic identification and in situ detection of individual microbial cells without cultivation. Microbiol Rev 59, 143-169.

Armitage, G. C. (1999). Development of a classification system for periodontal diseases and conditions. Ann Periodontol 4, 1-6.

Ashimoto, A., Chen, C., Bakker, I. \& Slots, J. (1996). Polymerase chain reaction detection of 8 putative periodontal pathogens in subgingival plaque of gingivitis and advanced periodontitis lesions. Oral Microbiol Immunol 11, 266-273.

Baumgartner, J. C., Bae, K. S., Xia, T., Whitt, J. \& David, L. L. (1999). Sodium dodecyl sulfate-polyacrylamide gel electrophoresis and polymerase chain reaction for differentiation of Prevotella intermedia and Prevotella nigrescens. J Endod 25, 324-328.

Bazin, H., Xhurdebise, L. M., Burtonboy, G., Lebacq, A. M., Clercq, L. D. \& Cormont, F. (1984). Rat monoclonal antibodies. I. Rapid purification from in vitro culture supernatants. I Immunol Methods 66, 261-269.

Brosius, J., Dull, T. L., Sleeter, D. D. \& Noller, H. F. (1981). Gene organization and primary structure of a ribosomal RNA operon from Escherichia coli. J Mol Biol 148, 107-127.

Conrads, G., Pelz, K., Hughes, B., Seyfarth, I. \& Devine, D. A. (1997). Optimized oligonucleotides for the differentiation of Prevotella intermedia and Prevotella nigrescens. Oral Microbiol Immunol 12, 117-120.

Dahlén, G., Wikström, M., Renvert, S., Gmür, R. \& Guggenheim, B. (1990). Biochemical and serological characterization of Bacteroides intermedius strains isolated from the deep periodontal pocket. J Clin Microbiol 28, 2269-2274.

Dahlén, G. G., Johnson, J. R. \& Gmür, R. (1996). Prevotella intermedia and Prevotella nigrescens serotypes, ribotypes and binding characteristics. FEMS Microbiol Lett 138, 89-95. 
Debelian, G. J., Olsen, I. \& Tronstad, L. (1996). Electrophoresis of whole-cell soluble proteins of microorganisms isolated from bacteremias in endodontic therapy. Eur J Oral Sci 104, 540-546.

Debelian, G. J., Olsen, I. \& Tronstad, L. (1997). Distinction of Prevotella intermedia and Prevotella nigrescens from endodontic bacteremia through their fatty acid content. Anaerobe 3, 61-68.

Frandsen, E. V. G., Poulsen, K. \& Kilian, M. (1995). Confirmation of the species Prevotella intermedia and Prevotella nigrescens. Int J Syst Bacteriol 45, 429-435.

Fuchs, B. M., Wallner, G., Beisker, W., Schwippl, I., Ludwig, W. \& Amann, R. (1998). Flow cytometric analysis of the in situ accessibility of Escherichia coli $16 \mathrm{~S}$ rRNA for fluorescently labeled oligonucleotide probes. Appl Environ Microbiol 64, 4973-4982.

Fukushima, H., Moroi, H., Inoue, J. \& 7 other authors (1992). Phenotypic characteristics and DNA relatedness in Prevotella intermedia and similar organisms. Oral Microbiol Immunol 7, 60-64.

Gharbia, S. E., Haapasalo, M., Shah, H. N., Kotiranta, A., Lounatmaa, K., Pearce, M. A. \& Devine, D. A. (1994). Characterization of Prevotella intermedia and Prevotella nigrescens isolates from periodontic and endodontic infections. J Periodont 65, 56-61.

Giertsen, E., Guggenheim, B., Thurnheer, T. \& Gmür, R. (2000). Microbiological aspects of an in situ model to study effects of antimicrobial agents on dental plaque ecology. Eur J Oral Sci 108, 403-411.

Gmür, R. (1995). Value of new serological probes for the study of putative periodontal pathogens. Carol Stream, IL: Quintessence Publishing.

Gmür, R. \& Guggenheim, B. (1983). Antigenic heterogeneity of Bacteroides intermedius as recognized by monoclonal antibodies. Infect Immun 42, 459-470.

Gmür, R. \& Guggenheim, B. (1994). Interdental supragingival plaque - a natural habitat of Actinobacillus actinomycetemcomitans, Bacteroides forsythus, Campylobacter rectus, and Prevotella nigrescens. J Dent Res 73, 1421-1428.

Gmür, R. \& Wyss, C. (1985). Monoclonal antibodies to characterize the antigenic heterogeneity of Bacteroides intermedius. In Monoclonal Antibodies Against Bacteria, vol. I, pp. 91-119. Edited by A. J. L. Macario \& E. Conway de Macario. New York: Academic Press.

Gmür, R., Werner-Felmayer, G. \& Guggenheim, B. (1988). Production and characterization of monoclonal antibodies specific for Bacteroides gingivalis. Oral Microbiol Immunol 3, 181-186.

Gmür, R., Strub, J. R. \& Guggenheim, B. (1989). Prevalence of Bacteroides forsythus and Bacteroides gingivalis in subgingival plaque of prosthodontically treated patients on short recall. J Periodont Res 24, 113-120.

Guillot, E. \& Mouton, C. (1997). PCR-DNA probe assays for identification and detection of Prevotella intermedia sensu stricto and Prevotella nigrescens. J Clin Microbiol 35, 1876-1882.

Haraldsson, G. \& Holbrook, W. P. (1999). Identifying clinically important Gram-negative anaerobes from the oral cavity. Eur J Oral Sci 107, 429-436.

Johnson, J. L. \& Holdeman, L. V. (1983). Bacteroides intermedius comb. nov. and description of Bacteroides corporis sp. nov. and Bacteroides levii sp. nov. Int J Syst Bacteriol 33, 15-25.

Könönen, E., Eerola, E., Frandsen, E. V. G., Jalava, J., Mättö, J., Salmenlinna, S. \& Jousimies-Somer, H. (1998). Phylogenetic characterization and proposal of new pigmented species to the genus Prevotella: Prevotella pallens sp. nov. Int J Syst Bacteriol 48, 47-51.

Lie, M. A., van der Weijden, G. A., Timmerman, M. F., Loos, B. G., van Steenbergen, T. J. M. \& van der Velden, U. (2001). Occurrence of Prevotella intermedia and Prevotella nigrescens in relation to gingivitis and gingival health. J Clin Periodontol 28, 189-193.

Loesche, W. J., Lopatin, D. E., Stoll, J., Vanpoperin, N. \& Hujoel, P. P. (1992). Comparison of various detection methods for periodontopathic bacteria - can culture be considered the primary reference standard? J Clin Microbiol 30, 370-376.

Maidak, B. L., Cole, J. R., Parker, C. T., Jr \& 11 other authors. (1999). A new version of the RDP (Ribosomal Database Project). Nucleic Acids Res 27, 171-173.

Manz, W. (1999). In situ analysis of microbial biofilms by rRNAtargeted oligonucleotide probing. Methods Enzymol 310, 79-91.

Mättö, J., Saarela, M., von Troil-Lindén, B., Alaluusua, S., Jousimies-Somer, H. \& Asikainen, S. (1996a). Similarity of salivary and subgingival Prevotella intermedia and Prevotella nigrescens isolates by arbitrarily primed polymerase chain reaction. Oral Microbiol Immunol 11, 395-401.

Mättö, J., Saarela, M., von Troil-Lindén, B., Könönen, E., Jousimies-Somer, H., Torkko, H., Alaluusua, S. \& Asikainen, S. (1996b). Distribution and genetic analysis of oral Prevotella intermedia and Prevotella nigrescens. Oral Microbiol Immunol 11, 96-102.

Moncla, B. J., Strockbine, L., Braham, P., Karlinsey, J. \& Roberts, M. C. (1988). The use of whole-cell DNA probes for the identification of Bacteroides intermedius isolates in a dot blot assay. J Dent Res 67, 1267-1270.

Moore, L. V. H., Moore, W. E. C., Cato, E. P., Smibert, R. M., Burmeister, J. A., Best, A. M. \& Ranney, R. R. (1987). Bacteriology of human gingivitis. J Dent Res 66, 989-995.

Moore, W. E. C. (1987). Microbiology of periodontal disease. J Periodont Res 22, 335-341.

Mullally, B. H., Dace, B., Shelburne, C. E., Wolff, L. F. \& Coulter, W. A. (2000). Prevalence of periodontal pathogens in localized and generalized forms of early-onset periodontitis. J Periodont Res 35, 232-241.

Nakazawa, F., Zambon, J. J., Reynolds, H. S. \& Genco, R. J. (1988). Serological studies of oral Bacteroides intermedius. Infect Immun 56, 1647-1651.

Paquet, C. \& Mouton, C. (1997). RAPD fingerprinting for the distinction of Prevotella intermedia sensu stricto from Prevotella nigrescens. Anaerobe 3, 271-278.

Premaraj, T., Kato, N., Fukui, K., Kato, H. \& Watanabe, K. (1999). Use of PCR and sodium dodecyl sulfate-polyacrylamide gel electrophoresis techniques for differentiation of Prevotella intermedia sensu stricto and Prevotella nigrescens. J Clin Microbiol 37, 1057-1064.

Riggio, M. P., Lennon, A. \& Roy, K. M. (1998). Detection of Prevotella intermedia in subgingival plaque of adult periodontitis patients by polymerase chain reaction. J Periodont Res 33, 369-376.

Robertson, K. L., Drucker, D. B., Blinkhorn, A. S. \& Davies, R. M. (1999). A comparison of techniques used to distinguish strains of Prevotella intermedia from Prevotella nigrescens. Anaerobe 5, 119-122.

Shah, H. N. \& Gharbia, S. E. (1992). Biochemical and chemical studies on strains designated Prevotella intermedia and proposal 
of a new pigmented species, Prevotella nigrescens sp. nov. Int J Syst Bacteriol 42, 542-546.

Siqueira, J. F., Rocas, I. N., Oliveira, J. C. M. \& Santos, K. R. N. (2001). Detection of putative oral pathogens in acute periradicular abscesses by $16 \mathrm{~S}$ rDNA-directed polymerase chain reaction. J Endod 27, 164-167.

Socransky, S. S., Smith, C., Martin, L., Paster, B. J., Dewhirst, F. E. \& Levin, A. E. (1994). 'Checkerboard' DNA-DNA hybridization. Biotechniques 17, 788-792.

Stubbs, S., Park, S. F., Bishop, P. A. \& Lewis, M. A. O. (1999). Direct detection of Prevotella intermedia and P. nigrescens in suppurative oral infection by amplification of $16 \mathrm{~S}$ rRNA gene. J Med Microbiol 48, 1017-1022.

Tanner, A. C. R., Maiden, M. F. J., Macuch, P. J., Murray, L. L. \& Kent, R. L. J. (1998). Microbiota of health, gingivitis, and initial periodontitis. J Clin Periodontol 25, 85-98.

Thurnheer, T., Gmür, R. \& Guggenheim, B. (2001). Automated fluorescent in situ hybridization for the specific detection and quantification of oral streptococci in dental plaque. J Microbiol Methods 44, 39-47.

van Steenbergen, T. J. M., Vlaanderen, C. A. \& de Graaff, J. (1982). Deoxyribonucleic acid homologies among strains of Bacteroides melaninogenicus and related species. J Appl Bacteriol 53, 269-276.

van Steenbergen, T. J. M., Bosch Tijhof, C. J., Petit, M. D. A. \& Van de Velden, U. (1997). Intra-familial transmission and distribution of Prevotella intermedia and Prevotella nigrescens. J Periodont Res 32, 345-350.

Wu, C.-C., Johnson, J.-L., Moore, W. E. C. \& Moore, L. V. H. (1992). Emended descriptions of Prevotella denticola, Prevotella loescheii, Prevotella veroralis, and Prevotella melaninogenica. Int J Syst Bacteriol 42, 536-541.

Received 28 September 2001; revised 7 January 2002; accepted 28 January 2002. 